\title{
IDENTIDADE DO PEDAGOGO: UMA ANÁLISE FENOMENOLÓGICO-HERMENÊUTICA
}

PEDAGOGUE'S IDENTITY: A PHENOMENOLOGICAL-HERMENEUTIC ANALISYS

\section{IDENTIDAD DEL PEDAGOGO: UNA ANÁLISIS FENOMENOLÓGICA-HERMENÉUTICA}

\author{
Ana Lúcia de Araújo Claro ${ }^{1}$ \\ Cláudia Sebastiana Rosa da Silva ${ }^{2}$ \\ Henrique Costa Brojato ${ }^{3}$
}

\begin{abstract}
Resumo: Este artigo objetiva analisar criticamente como os pedagogos escolares participantes de um programa de formação continuada compreendem a construção da sua identidade profissional em seu cotidiano de atuação. A análise de cunho fenomenológico hermenêutico, utilizou o protocolo de observação de um dos encontros do programa de formação continuada intitulado "Identidade profissional do pedagogo" e memoriais construídos pelos 16 pedagogos como instrumentos de pesquisa. Infere-se que a identidade dos pedagogos se apresenta como um processo em construção, sendo materializada no fazer pedagógico, na prática educativa, mas por outro lado engendra em situações por vezes contraditórias de resistência, acúmulo de atribuições e estado de solidão, afinal, são profissionais responsáveis pela sua própria formação e pela formação do professor.
\end{abstract}

Palavras-chave: Educação; pedagogo escolar; identidade profissional.

\begin{abstract}
This article aims to critically analyze how the school pedagogues' participants of a continuous education program comprehend the construction of their professional identity in their daily work. The phenomenological-hermeneutic analysis, used the observation protocol of one of the meetings of the continuous education program named "Pedagogue's Professional Identity" and memorials built by 16 pedagogues as research instruments. It is inferred that the pedagogue's identity shows itself as a process under construction, which is being materialized in the pedagogical practice, in the educational practice, but on the other hand the identity process engenders in situations sometimes contradictory of resistance, accumulation of assignments and a state of solitude, after all, they are professionals responsible for their own education and for teacher education.
\end{abstract}

Keywords: Education; school pedagogue; professional identity.

Resumen: Este artículo tiene como objetivo analizar críticamente cómo los pedagogos escolares que participan en un programa de educación continua comprenden la construcción de su identidad profesional en su trabajo diario. El análisis fenomenológico-hermenéutica utilizó el protocolo de observación de uno de los encuentros del programa de educación continua titulado "Identidad profesional del pedagogo" y memoriales construidos por los 16 pedagogos como instrumentos de investigación. Se infiere que la identidad de los pedagogos se presenta como un proceso en construcción, que se materializa en la práctica pedagógica, en la práctica educativa, pero por otro lado se engendra en situaciones en ocasiones contradictorias de resistencias, acumulación de atribuciones y un estado de soledad, al fin y al cabo, son profesionales responsables de su propia formación y de la formación del profesorado.

Palabras clave: Educación; pedagogo escolar; identidad profesional.

\footnotetext{
${ }^{1}$ Pontifícia Universidade Católica do Paraná

${ }^{2}$ Pontifícia Universidade Católica do Paraná

${ }^{3}$ Pontifícia Universidade Católica do Paraná
} 


\section{Introdução}

Este artigo aborda a questão da construção da identidade profissional de pedagogos escolares, de diferentes seguimentos de atuação, participantes de um programa de formação continuada. Esse tema surge em um contexto de constantes incertezas vivenciadas pelos profissionais, relacionadas aos desafios cotidianos, que demandam por aprofundamentos e definições sobre os limites e potencialidades de sua atuação. Portanto, esta pesquisa ${ }^{4}$ teve como objetivo analisar criticamente como os pedagogos escolares participantes de um programa de formação continuada compreendem a construção da sua identidade profissional em seu cotidiano de atuação.

$O$ interesse de investigar essa temática emerge a partir dos estudos desenvolvidos pelo grupo de pesquisadores vinculados à Linha de pesquisa "Teoria e Prática na Formação Docente" e ao projeto de pesquisa intitulado "Aprendizagem, Conhecimento e Identidade do Pedagogo", desenvolvido no período de 2018 a 2020, por meio do Programa de Pós-Graduação em Educação da Pontifícia Universidade Católica do Paraná (PUCPR). A metodologia tem um cunho fenomenológico hermenêutico, utilizou o protocolo de observação de um dos encontros do programa de formação continuada intitulado "Identidade profissional do pedagogo" e memoriais construídos pelos 16 pedagogos como instrumentos de pesquisa.

A importância desta análise se dá pelo pedagogo constituir-se como um profissional fundamental na organização do trabalho pedagógico. É ele quem orienta, organiza e articula os momentos de reflexão teórica, relacionados às situações do cotidiano escolar. É um profissional que lida com os fatos, os contextos e as situações relacionados com sua prática educativa (LIBÂNEO, 2001).

A organização desse artigo se constitui da seguinte maneira: inicialmente discute-se o conceito de identidade a partir de teóricos como Dubar (1997), Ferreira e Pooli (2017) Da Silva (2013) e Real (2019) e explora-se o conceito sobre identidade profissional do pedagogo. Na sequência apresenta-se a metodologia de pesquisa, seguida pela descrição e análise dos dados e as considerações finais.

\section{Identidade profissional do pedagogo}

A identidade é concebida como um processo de sucessivas socializações e, portanto, aberta a muitas interpretações. No contexto atual, os sujeitos vivenciam crises das identidades, fenômeno que pode estar relacionado com "a teorização da crise econômica que o mundo ocidental acaba de atravessar" (DUBAR, 1997, p. 21). Entretanto, o autor ressalta que não se pode atribuir essa crise somente às questões econômicas, pois existem outros aspectos que podem estar atrelados a essas mudanças, especialmente as novas configurações das relações sociais.

Na perspectiva de Ferreira e Pooli (2017, p. 21) a identidade pode ser compreendida como uma forma de "acolhimento, pertencimento, vinculação ou mesmo de relacionamentos. É uma forma de ancorar nossas expectativas e angústias dando-lhe um porto seguro, mesmo que o mar da contemporaneidade esteja envolto em constantes tempestades". Assim sendo, tais crises identitárias fazem parte da sociedade contemporânea e essas transformações podem desencadear incertezas, ansiedades e angústias. Pode-se inferir que tais sentimentos e percepções sobre essas constantes mudanças trazem implicações no processo de construção das identidades, sejam elas pessoais ou profissionais.

\footnotetext{
${ }^{4}$ Pesquisa integrada ao projeto intitulado "Aprendizagem, Conhecimento e Identidade do Pedagogo", desenvolvido no período de 2018 a 2020, por meio do Programa de Pós-Graduação em Educação da Pontifícia Universidade Católica do Paraná (PUCPR).
} 
Em se tratando do pedagogo, sua identidade vai se constituindo "por uma forma de saberdomínio do conhecimento, objeto de campo, de ser-atribuições da ordem ética e deontológica, de fazer-domínio dos saberes da prática profissional" (BRZEZINSKI, 2011, p. 4). Portanto, são saberes que se constituem como base para a consolidação da prática educativa, entre o fazer e o saber do pedagogo escolar no seu cotidiano escolar.

Assim sendo, a identidade profissional é o que caracteriza o indivíduo para exercer determinada função. Além disso, o autor destaca que a identidade se constitui como um processo reflexivo e que sofre influências significativas da nossa identidade pessoal e social (REAL, 2019).

Da Silva (2013, p. 116) afirma que a identidade do pedagogo se constitui "diariamente num processo histórico, dialético e social". Ainda, que a identidade não é algo inato ou adquirido, mas sim um processo em permanente reconstrução e ressignificação da singularidade do pedagogo que vai sendo configurada pelas experiências em sua prática educativa.

Diante dessas questões, se faz necessário compreender como a identidade profissional do pedagogo escolar se constitui, principalmente, por meio dos sentidos e significados trazidos por eles, caminhando para leituras possíveis sobre a importância da formação continuada e da práxis cotidiana nos diversos contextos escolares.

\section{A metodologia de pesquisa}

A metodologia adotada para este estudo se fundamenta na abordagem fenomenológicohermenêutica. Sendo assim, todas as ações, falas, bem como circunstâncias de local, condições físicas e emocionais dos sujeitos envolvidos são consideradas a partir do olhar do pesquisador integrado no fenômeno (GADAMER, 2007). Os dados colhidos são interpretados como fenômenos, que se evidenciam num dado momento para interpretar a dinâmica dos acontecimentos apresentados por meio de valores, posicionamentos, crenças, atitudes e intenções, fruto das relações intersubjetivas humanas.

Esta epistemologia apresenta-se como de natureza exploratória, ou seja, uma interpretação aberta a outras interpretações, buscando ver, de forma contextualizada aquilo que se apresenta. Por meio dela é possível tratar os significados contextuais, a historicidade e a comunicação do conhecimento das ciências humanas. Isso se dá na atitude interpretativa, onde o sujeito e o objeto só podem ser compreendidos por meio da linguagem, que é fruto tanto do pensamento, como das experiências práticas que se mostram no discurso e das relações estabelecidas no fenômeno.

Os instrumentos utilizados para a análise foram o protocolo de observação de um encontro de formação continuada e o memorial descritivo. Por meio do protocolo de observação absorveu-se os três modos de ser do fenômeno como ele se apresenta a partir do que é dito, do que é manifestado por meio da linguagem corporal e do mundo exterior (PICHON-RIVIERE, 1986). Os registros em protocolo de observação foram realizados por dois pesquisadores, que ao final do registro aproximaram os dados observados, agrupando-os, descrevendo-os e interpretando-os, procurando responder aos objetivos deste artigo.

Já os memoriais descritivos tratava-se de relatos feitos pelos pedagogos escolares sobre a sua trajetória pessoal e profissional. Neles estavam os motivos da escolha pela profissão, os acontecimentos mais significantes na sua caminhada pessoal e profissional por meio de uma narrativa escrita e individual, oportunizando a atitude reflexiva e consequente compreensão de si mesmo no processo da respectiva construção profissional. A consigna ${ }^{5}$ apresentada para a construção do memorial foi: "Você fará uma narrativa escrita, contando sua história profissional, de tal forma que destaque os momentos mais importantes da aprendizagem que viveu (em família,

\footnotetext{
${ }^{5} \mathrm{O}$ termo consigna refere-se à "maneira como se formula o pedido da tarefa, que ao ser oferecida pelo grupo, promove algum tipo de mobilização de ação do grupo" (PORTILHO et al., 2018, p. 59).
} 
com amigos, na escolha - desde a educação infantil até sua formatura e primeiras ações profissionais) que tenham contribuído para a formação do profissional que você é hoje".

A partir destes instrumentos de pesquisa, os aspectos relacionados à construção da identidade profissional do pedagogo no seu cotidiano da atuação foram agrupados e analisados, procurando captar os sentidos que esses sujeitos revelam. Buscando respeitar os princípios éticos em pesquisa, os profissionais não terão suas identidades reveladas, sendo nomeados pela letra $\mathrm{P}$ seguida de um número.

Este estudo foi aprovado pelo Comitê de Ética em Pesquisas com Seres Humanos da PUC-PR (CAAE no 87390517.8.0000.0020).

\section{Descrição e interpretação dos dados}

Na leitura dos memoriais, apreendeu-se no horizonte hermenêutico que a forma como cada pessoa define a identidade profissional dos pedagogos se apresenta de maneiras distintas. Observou-se nos relatos que a identidade profissional é atravessada por memórias da infância, por meio de brincadeiras e relações - ora positivas, ora negativas - e que algumas expectativas já eram criadas em relação ao ser professor na relação com os familiares dos pedagogos, conforme ilustrado nos trechos dos seus memoriais:

Da Educação Infantil, a formação em Magistério, cresci numa única escola - Instituto de Educação do Paraná - minha mãe também trabalhou nesta instituição, então eu sempre "me senti em casa". Me sentia acolhida pelos Professores e sempre admirei a competência deles (P8).

Terminei o ginásio, minhas irmãs então professoras em uma cidade pequena me incentivaram a fazer o magistério e lá fui eu. No terceiro ano elas arrumaram uma escola para eu começar a dar aulas no município. No começo, não gostei nenhum pouco, mas foram se passando os anos e eu percebi que tinha nascido para ser professora (P3).

No ensino médio minha mãe me matriculou no magistério, pois seu sonho era ser professora não conseguiu concretizar tão sonho devido a várias situações, então se realizaria tendo uma filha professora, lembro com um misto de alegria que os primeiros dias ia e volta do colégio chorando pensava que minha timidez era um empecilho para eu ser professora, conversei com mamãe e está pontuou que seria uma superação da timidez que ser professora era maravilhoso. $\mathrm{Na}$ verdade, me apaixonei pela profissão ao cursar Adicionais de Educação infantil, foi a partir desse curso que escolhi cursar Pedagogia (P6).

Minha trajetória histórica profissional, simplesmente, se traduz a grandes pessoas que tive como referência e grandes exemplos dentro da família. Desde meus primeiros anos de vida escolar, numa escola rural denominada Escola Municipal Princesa Isabel, município de Assis Chateaubriand, oeste do Paraná, região onde vivi minha infância e juventude, tive o privilégio de ter como professoras duas tias, Tia Dina $\left(1^{a}\right.$ e $2^{a}$ séries $)$ e tia Ramira $\left(3^{a}\right.$ e $4^{a}$ séries $)$, estas, irmãs de meu pai (em memória) que além de me alfabetizarem, também me ensinaram o caminho do bem, os valores da humanidade, entre estes, o respeito que eu e meus colegas de classe deveríamos ter por aqueles/as que ensinam todos os dias à várias crianças e jovens, o conhecimento para a vida - Os/As professores/as. Acredito que tais ensinamentos oriundos de pessoas amáveis e inspiradoras, comungados aos momentos felizes dessa fase me levaram a escolher a docência como profissão (P13). 
Compreende-se, a partir dos relatos, que tais expectativas sobre a futura profissão foram tomando forma por meio da formação inicial, geralmente no magistério, assim como por meio de figuras significativas que fizeram parte do processo educativo de cada participante, habitualmente identificado como professores. Contudo, a análise dos instrumentos também demonstrou que, ao assumir a função de pedagogo escolar, diversos desafios se apresentaram para cada participante devido ao ser-pedagogo se distanciar da construção previamente idealizada, desde as lembranças infantis, até as vivências da formação inicial, da atuação como professor ou em outra função administrativa escolar.

Também houve relatos em que a temporalidade mnêmica se mostrou mais restrita ao momento da formação inicial, seja ela do magistério, seja a partir do ensino superior, no curso de pedagogia. Nesses memoriais, a construção do que vem a ser a identidade do pedagogo apresentou diversos desafios, que estão atrelados à generalidade da Licenciatura em Pedagogia, afinal, atuam nesse campo não somente profissionais que se ocupam de domínios educativos, mas também aqueles que se dedicam às "atividades de pesquisa, documentação, formação profissional, gestão de sistemas escolares e escolas, coordenação pedagógica, animação sociocultural, formação continuada em empresas, escolas e outras instituições" (LIBÂNEO, 2010, p. 37).

O curso de Pedagogia não revela, historicamente, uma identidade esclarecedora a respeito da atuação do profissional pedagogo, desde sua formação geral até as habilitações específicas, como evidenciadas por Libâneo (2010). Na busca por suprir as necessidades educacionais vividas nos diferentes momentos históricos, o pedagogo torna-se um profissional ora especialista, ora generalista, por isso, há a necessidade de especificar o pedagogo que atua na escola, reconhecendo-o como pedagogo escolar e como acontece sua formação continuada.

Esse fenômeno foi observado em falas relacionadas à diversidade da prática do pedagogo, que, apesar de terem sido relatadas nos memoriais como momentos de grande aprendizado por aquelas que atuaram nesses contextos diversos, apontaram o quanto a formação inicial do pedagogo deveria abarcar tal diversidade.

$\mathrm{Na}$ roda de conversa vivenciada pelos pedagogos no encontro de formação, os participantes deveriam discutir sobre a identidade profissional do pedagogo. Alguns trechos das falas ilustram suas percepções:

Acho que ainda está em um processo de construção. [...] O pedagogo ficou uma coisa mais eclética, meio quem faz tudo, o próprio curso nos dá um leque muito grande de atuação (P13).

É ainda difícil de se articular, de deixar claro, e qual é a função, qual é o meu fazer de pedagogo. Já vem de uma formação que é uma formação junto com a docência, de uma carreira que as vezes está ligada com a docência, é algo não é um conceito claro, a gente entende que algumas tarefas são pertinentes do fazer do pedagogo, mas quando a gente fala de identidade profissional é algo [...] bastante subjetivo, até mesmo para nós pedagogos (P5).

Para mim é tentar ser especialista em prática educativa, pensar em como eu organizo o processo para que o sujeito possa aprender, que condições esse sujeito precisa ter (P10).

É fenomenologicamente evidente, no diálogo hermenêutico realizado, que a desigualdade social nos contextos de atuação, assim como a forma como cada instituição estabelece o que é a função do pedagogo, também se apresentam como pontos de estranhamento/distanciamento do processo de apreensão identitária do ser-pedagogo. No caso da desigualdade social, os pedagogos se viram nos relatos frente a demandas de mediação, que muitas vezes não percebem como pertencentes ao processo de qualificação do ensino e da aprendizagem da comunidade escolar (PINTO, 2011). 
Já em relação à construção da função em cada contexto, percebeu-se muitas vezes que a escola apresenta um espaço vivencial da profissão deslocado da ideia que cada pedagogo idealizou sobre sua identidade profissional, com demandas burocráticas e mediações na ausência de professores, impactando diretamente na construção - ou confusão - identitária por meio de uma restrição espaço-temporal. E esse processo de restrição, que se dá por meio da linguagem a partir da cultura de cada instituição escolar, acaba por prejudicar a identificação entre a pessoa que atua como pedagogo e aquilo que se dá na vivência de cada contexto de atuação. Nesse sentido, a cultura escolar se articula nos seguintes aspectos:

Nas práticas e rituais da ação educativa; [...] No ritmo em que as aulas são organizadas, nos modos, normas e instruções de relação e comunicação didática na aula, entre professores e alunos e entre os alunos; Nos modos organizativos, formais (direção, assembleias) e informais (formas de tratamento, saudações, atitudes, grupos, conflitos, formas de comunicação), modos de funcionamento do corpo docente e relações entre seus atores professores, alunos e famílias; Nos discursos, palavras, expressões, frases, modos de comunicação, representações mentais e rituais que dão sentido e coesão ao conjunto (VIÑAO FRAGO, 2001, p. 30).

A escola, por mais que esteja integrada e sujeita a contextos socioculturais mais amplos, produz sua cultura interna revelada por meio de valores, representações, expectativas e crenças dos diferentes atores que ali transitam e, portanto, a cultura escolar não é imposta ao ambiente, mas se constrói e se desenvolve na interação social (NÓVOA, 1995).

Logo, num exercício fenomenológico hermenêutico, chegou-se ao sentido próprio do modo de apreensão do que vem a ser a identidade do pedagogo junto aos participantes. Podese compreender, num horizonte hermenêutico, que a identidade do pedagogo é vista por esses profissionais como processo em construção, que não se limita a uma forma definitiva de serpedagogo, mas que se abre de forma eclética e diversa a diferentes contextos de atuação, mesmo considerando apenas o contexto escolar. Por isso, esse sentido profundo do fenômeno identitário precisa ser o ponto de partida para a abertura à transformação da prática cotidiana, para que cada pedagogo possa vir-a-ser não a partir do fechamento identitário em-si, mas por meio de uma abertura para sofrer transformações individuais, que reflitam na construção de maior autonomia diante do seu fazer cotidiano.

\section{Algumas considerações}

Com base nas análises realizadas, foi possível observar aproximação com a literatura sobre o assunto, já que a identidade dos pedagogos se apresentou, a partir da descrição e interpretação dos memoriais e do protocolo de observação de um dos encontros do programa de formação continuada, como um processo em construção, um devir-a-ser, pois é construída na prática e no fazer cotidianos, sendo na organização do próprio trabalho pedagógico que o devir-a-ser característico da identidade profissional se constitui.

Considera-se que a identidade profissional do pedagogo escolar se engendra em situações por vezes contraditórias de resistência, acúmulo de atribuições e estado de solidão e, que ele reconhece a sua importância como profissional responsável pela formação do professor e busca por formação específica para si mesmo. É o profissional essencial para que a vida na escola aconteça, pois é ele quem dá suporte às iniciativas pedagógicas dos professores, ao mesmo tempo em que articula as orientações advindas da rede de ensino ou da direção escolar, buscando atender às necessidades dos 
estudantes e demais membros da comunidade escolar. Portanto, necessita de formação continuada que oportunize a reconstrução da sua identidade de forma permanente.

A formação continuada de pedagogos escolares precisa estar atrelada a uma instituição aprendente, aquela que valoriza a experiência desses profissionais da educação, bem como cria condições para que eles participem da tomada de decisões, princípio de uma escola democrática. Para tanto, é preciso que participem coletivamente da construção do projeto pedagógico e que possam conhecer a realidade da escola, assim como os limites da sua ação para poder escolher alternativas adequadas àquele contexto, a fim de proporcionar o envolvimento e compromisso de todos os profissionais da instituição na ação, especialmente, gestão, pedagogos e professores.

Nesse sentido, Pimenta (1999) reitera que a identidade do pedagogo se constrói por meio da análise permanente dos significados sociais da profissão, na validação de práticas significativas consagradas culturalmente. Mas também, a identidade do pedagogo vai sendo construída nas relações estabelecidas, nos contextos e instituições que faz parte, na construção dos sentimentos de pertença, na participação e construção profissionais como seres históricos (LINS, 2016).

\section{Referências}

BRZEZINSKI, I. Pedagogo: delineando identidade(s). Revista UFG, ano XIII, n. 10, p. 120-132, jul. 2011. Disponível em https://files.cercomp.ufg.br/weby/up/694/o/10_iria_brzezinski.pdf. Acesso em: 11 out. 2021.

DA SILVA, V. Processos construtivos da identidade profissional do pedagogo: formação inicial, prática profissional e políticas públicas. 2013. 163 p. (Dissertação de Mestrado) - Centro de Educação, Programa de Pós- Graduação em Educação, Universidade Federal de Santa Maria, 2013.

DUBAR, C. A socialização: construção das identidades sociais e profissionais. Porto: Porto Editora, 1997.

FERREIRA, V. M. R.; POOLI, J. P.; Pedagogos construindo suas identidades: entre a discrição e escolhas. Educar em Revista, Curitiba, ed. especial, n. 1, p. 19-37, jun. 2017. Disponível em https://www.scielo.br/j/er/a/zmSqiyP7HfB8F6XxcLL8LNN/abstract/?lang=pt. Acesso em 11 out. 2021.

GADAMER, H. Hermenêutica em retrospectiva. Petrópolis: Vozes, 2007.

LIBÂNEO, J. C. Pedagogia e pedagogos: inquietações e buscas. Educar, Curitiba, n. 17, p. 153 176, 2001.

LIBÂNEO, J. C. Pedagogia e pedagogos, para quê? São Paulo: Cortez, 2010.

LINS, J. B. O coordenador pedagógico e a construção da sua identidade profissional. 2016. 111f. Dissertação (Mestrado em Educação) - Programa de Pós-Graduação em Educação, Universidade Federal de Pernambuco, Recife, 2016.

NÓVOA, A. As organizações escolares em análise. Lisboa: Nova Enciclopédia, 1995.

PICHON-RIVIÈRE, E. Teoria do vínculo. São Paulo: Martins Fontes, 1986. 
PIMENTA, S. G. Formação de professores: identidade e saberes da docência. In: PIMENTA, S. G. (Org.). Saberes pedagógicos e atividade docente. São Paulo: Cortez Editora, 1999. p. 15-34

PINTO, U. A. Pedagogia escolar: coordenação pedagógica e gestão educacional. São Paulo: Cortez, 2011.

PORTILHO, E. M. L. et al. A instituição que aprende sob o olhar da psicopedagogia. Rio de Janeiro: Wak Editora, 2018.

REAL, H. R. A identidade profissional do pedagogo escolar em formação continuada. 2019. 97f. Dissertação (Mestrado em Educação) - Programa de Pós-Graduação em Educação, Pontifícia Universidade Católica do Paraná, Curitiba, 2019.

VIÑAO FRAGO, A. Fracasan las reformas educativas?: la respuesta de un historiador. In: SOCIEDADE BRASILEIRA DE HISTÓRIA DA EDUCAÇÃO (Org.). Educação brasileira: história e historiografia. Campinas: Autores Associados: São Paulo, 2001. p. 21-52.

\section{Sobre os autores}

Ana Lúcia de Araújo Claro. Mestre em Educação (UTPPR), Especialista em Coordenação/ Supervisão (PUCMG) e em Psicopedagogia (PUCPR). Pedagoga e pesquisadora do Grupo de Pesquisa: Aprendizagem e Conhecimento na Prática Docente, da PUCPR / Curitiba, Paraná, Brasil. E-mail: ana.claro13@hotmail.com.

Cláudia Sebastiana Rosa da Silva. Doutora em Educação (PUCPR), mestre em Educação (PUCPR), especialista em Educação Infantil e Séries Iniciais (IBPEX) e em Psicopedagogia (PUCPR). Pedagoga e pesquisadora do Grupo de Pesquisa: Aprendizagem e Conhecimento na Prática Docente (PUCPR) / Curitiba, Paraná, Brasil.

E-mail: clausers@gmail.com.

Henrique Costa Brojato. Psicólogo, mestre em Educação (PUCPR), pesquisador do Grupo de Pesquisa: Aprendizagem e Conhecimento na Prática Docente (PUCPR) / Curitiba, Paraná, Brasil. E-mail: costabrojato@gmail.com. 